\title{
Нормативно-Политические Вопросы Обращение С Обеспечением Низкого Образования В Индонезии (Policy In Handling The Low Education Relevance In Indonesia)*
}

\author{
Indrayanto, ${ }^{1}$ Smyshlyaeva Larisa Germanovna ${ }^{2}$ \\ Tomsk State Pedagogical University, Russian Federation \\ $\underline{10.15408 / \text { jch.v8i2.16505 }}$
}

\begin{abstract}
The problem of Human Resources (HR) in Indonesia is becoming increasingly complex, this is reflected in the large number of formal education graduates from various levels who are not absorbed in the world of work. Many factors cause this to happen, including the mismatch between HR competencies and the labor market, the growth of the workforce is greater than the availability of available employment and population distribution between regions is not evenly distributed. If you look at the achievements of Indonesian tertiary education graduates, many of Indonesian tertiary education graduates are slow to get jobs, this shows that there is a broken link between higher education and the world of work. Higher education has not been able to produce graduates with high selling prices armed with the knowledge they have learned even though in general higher education graduates have greater employment opportunities than high school or lower level graduates. Many realities on the ground show that the quality of Indonesian people as a potential resource still does not meet expectations. This happens because of the low quality of education in Indonesia. By fulfilling good educational needs, the students will get benefits and can improve the quality of life of the knowledge they have, so that after completing their education, they can get decent jobs or create quality jobs. Indonesia's education world must start to build links with the world of work, so that the world of work responds to graduates produced in accordance with what the world of work wants; this paradigm must be understood and built by the Indonesian government. Education transformation is needed so that education is able to produce reliable and resilient human resources; education and educators must be improved.
\end{abstract}

Keyword: Education; Policy; Indonesia

\footnotetext{
* Received: January 16, 2020, revised: March 23, 2020, accepted: July 22, 2020, Published: August $1,2020$.

${ }^{1}$ Indrayanto is a PhD Student at Tomsk State Pedagogical University, Russia, and a member of the Eurasian Researchers and Scholars Institute at Russia.

2 Larisa Germanovna Smyshlyaeva, Professor, DSc in Pedagogic sciences, the Head of the Department. Tomsk State Pedagogical University, Russia. E-mail: laris.s@mail.ru.

Correspoding E-mail: indrayanto@tspu.edu.ru.
} 


\section{Kebijakan Dalam Menangani Rendahnya Relevansi Pendidikan Di Indonesia}

\section{Abstrak:}

Permasalahan Sumber Daya Manusia (SDM) di Indonesia menjadi semakin kompleks, hal ini tercermin dengan banyaknya para lulusan pendidikan formal dari berbagai jenjang yang tidak terserap dalam dunia kerja. Banyak factor yang menyebabkan hal ini terjadi, diantaranya yaitu ketidaksesuaian antara kompetensi SDM dengan pasar kerja, pertumbuhan angkatan kerja lebih besar dari ketersediaan lapangan kerja yang ada serta ditribusi penduduk antar daerah belum merata. Jika melihat dari capaian para lulusan pendidikan tinggi Indonesia, banyak dari lulusan perguruan tinggi di Indonesia lambat mendapatkan pekerjaan, Ini menunjukkan terdapatnya mata rantai yang putus antara pendidikan tinggi dan dunia kerja. Perguruan tinggi belum mampu menghasilkan lulusan dengan harga jual yang tinggi berbekal dengan ilmu yang telah dipelajari meskipun secara umum lulusan pendidikan tinggi memiliki peluang kerja lebih besar dibanding lulusan tingkat SMA ataupun lebih rendah lagi. Banyak realita di lapangan yang menunjukkan bahwa kualitas masyarakat Indonesia sebagai sumber daya yang potensial masih belum memenuhi harapan. Hal ini terjadi dikarenakan rendahnya kualitas pendidikan di Indonesia. Dengan terpenuhi kebutuhan pendidikan yang baik, siswa-siswa peserta didik tersebut akan mendapatkan manfaat dan dapat meningkatkan kualitas hidup dari pengetahuan yang dimiliki, sehingga setelah menyelesaikan pendidikannya, mereka dapat memperoleh pekerjaan yang layak atau menciptakan lapangan kerja yang berkualitas. Dunia pendidikan Indonesia haruslah memulai untuk membangun mata rantai dengan dunia kerja, sehngga respon dunia kerja terhadap lulusan yang dihasilkan sesuai dengan yang diinginkan dunia kerja; paradigma seperti ini harus dipahami dan dibangun oleh pemerintah Indonesia.Transformasi pendidikan diperlukan agar pendidikan mampu menghasilkan sumber daya manusia yang handal dan tangguh; pendidikan dan tenaga pendidik harus ditingkatkan.

Kata Kunci: Pendidikan; Kebijakan; Indonesia

\section{Политика В Обработке Низкого Образования В Индонезии}

\section{Аннотация}

Проблема человеческих ресурсов в Индонезии становится все более сложной, что отражается в большом количестве выпускников формального образования разных уровней, которые не поглощены работой. Это обусловлено многими факторами, в том числе несоответствием между компетенциями в области людских ресурсов и рынком труда, рост рабочей силы превышает доступную занятость, а распределение населения между регионами распределяется неравномерно. Если вы посмотрите на достижения индонезийских выпускников высших учебных заведений, многие выпускники высших учебных заведений в Индонезии не могут найти работу, и это показывает, что существует разрывная связь между высшим образованием и миром труда. Высшее образование не смогло подготовить выпускников с высокими отпускными ценами, вооруженных знаниями, которые они узнали, хотя в целом выпускники высших учебных заведений имеют более широкие возможности трудоустройства, чем выпускники старших классов. Многие реалии на местах показывают, что качество индонезийского народа как потенциального ресурса все еще не соответствует ожиданиям. Это происходит из-за низкого качества образования в Индонезии. Выполняя хорошие образовательные потребности, студенты получают преимущества и могут улучшить качество жизни знаний, которые они имеют, так что после завершения обучения они могут получить достойную работу или создать качественную работу. Мир образования Индонезии должен начать строить связи с миром труда, чтобы мир труда реагировал на выпускников, произведенных в соответствии с тем, что хочет мир труда; эта парадигма должна быть понята и построена правительством Индонезии: трансформация образования необходима для того, чтобы образование могло производить надежные и устойчивые человеческие ресурсы; образование и воспитатели должны быть улучшены.

Ключевые слова: образование; Политика; Индонезия 
Нормативно-Политические Вопросы Обращение С Обеспечением Низкого Образования В Индонезии (Policy In Handling The Low Education Relevance In Indonesia)

\section{А. ВВЕДЕНИЕ}

Чтобы лучше понять эту статью, я объясню заранее о структуре образования в Индонезии шкодьная система Индонезии очень отдичается в России, ни в бодьшинстве стран Европы. Образование в Индонезии - это все образование, которое проводилось в Индонезии, либо структурированное, либо неструктурированное. В целом, за образование в Индонезии отвечает Министерство образования и культуры Республики Индонезия. И формальное образование на основе религиозных быть ответственность Министерства по делам религий Республики Индонезия.

В Индонезии все жители должны следовать программе обязательного базового образования в течение девяти лет, шести лет в начальной школе и трех лет в средней школе. В настоящее время образование в Индонезии регулируется законом № 202003 года О Национальной системе образования. (Wikipedia-Indonesia). Образование в Индонезии делится на три основных направления: формальное, неформальное и неформальное. Образование также делится на четыре уровня: раннее детство, начадьное образование, среднее образование и высшее образование.

Уровень образования - это ступень образования, которая устанавливается на основе уровня развития обучающихся, целей, которые должны быть достигнуты, и выработанных навыков. а.) “Образование в раннем детстве " (дошкодьное образование) программы образования в раннем детстве, образование в раннем детстве - это усилия по развитию, которые предназначены для детей от рождения до возраста шести лет, проводимые посредством предоставления образовательной стимуляции для содействия росту и развитию физического и духовного, чтобы дети были готовы к поступлению в дальнейшее образование. b.) Базовое образование. Базовое образование - это уровень раннего образования в течение 9 лет, т. е. начальная школа $\left(\mathrm{SD}^{3} / \mathrm{MI}^{4}\right)$ в течение 6 иет и младшая

${ }^{3}$ Начальная школа (SD; английский язык: Elementary School или Primary School) является самым базовым уровнем в формальном образовании в Индонезии. Начальная школа занимает 6 лет, начиная с 1 класса до 6 класса. В настоящее время учащиеся 6 класса обязаны сдавать национальные экзамены (Ebtanas), которые влияют на окончание учебы. Выпускники начальной школы могут продолжить свое образование до уровня средней школы в первую очередь. Учащиеся начальных классов в возрасте 6-12 лет. В Индонезии каждый гражданин в возрасте от 6 до 15 лет имеет обязательное базовое образование, т. е. начальную школу (или эквивалент) 6 лет и среднюю школу (или эквивалент) 3 года. Начальная школа организуется правительством или частным сектором.

4 Madrasah ibtidaiyah (сокращенно MI) является самым базовым уровнем формального образования в Индонезии, эквивалентом начальной школы, которая управляется министерством по 
средняя школа (SMP5 /MTs ${ }^{6}$ ) в течение 3 лет. Базовое образование является обязательным. с.) Среднее образование. Среднее образование - это уровень образования продвинутое базовое образование, т. е. Высшая Средняя школа (SMA $\left.{ }^{7} / \mathrm{SMK}^{8} / \mathrm{MA}^{9}\right)$ в течение 3 лет обучения во время путешествия. д.) Высшее образование. Высшее образование - это образование после получения среднего образования, которое включает курсы диплома, бакалавриата, магистратуры, докторантуры и специалистов, организуемые колледжем.

\begin{tabular}{|c|c|c|c|c|}
\hline Т.К.[8] & $\begin{array}{c}\text { ОСНОВНАЯ } \\
\text { ШКОЛА }\end{array}$ & $\begin{array}{c}\text { ОСНОВНАЯ } \\
\text { СРЕДНЯЯ } \\
\text { ШКОЛА }\end{array}$ & $\begin{array}{c}\text { СРЕДНЯЯ } \\
\text { ШКОЛА }\end{array}$ & ВЫСОКОЕ ОБРАЗОВАНИЕ \\
\hline
\end{tabular}

делам религий. Обучение в начальной школе занимает 6 лет, начиная с 1-го по 6-й класс. Учебная программа Madrasah ibtidaiyah партнер с начальной школьной программой, только в Ml есть часть больше об Исламском религиозном образовании.

${ }^{5}$ Средняя школа (SMP, английский: Junior High School или Middle School) - это основное образование в формальном образовании в Индонезии после окончания начальной школы (или эквивалента). Средняя школа в 3 года, начиная с 7-го класса до 9-го класса. В Индонезии каждый гражданин в возрасте 7-15 лет должен посещать базовое образование, т. е. начальную школу (или эквивалентную) 6 лет и среднюю школу (или эквивалентную) 3 года.

6 Madrasah Tsanawiyah (сокращенно MTs) является базовым уровнем формального образования в Индонезии, эквивалентом средней школы, управляемой Министерством по делам религий. Обучение в младшей средней школе занимает 3 года, начиная с 7 класса до 9 класса. Учащиеся 9 класса обязаны сдавать национальные экзамены (ранее Ebtanas), которые влияют на окончание учебы. Выпускники MTs могут продолжить свое образование в медресе Алия или старшей средней школе / профессионально-техническом училище. Учебный план медресе цанавия совпадает с учебным планом средних школ, только на МТs есть часть больше об Исламском религиозном образовании.

${ }^{7}$ Старшая средняя школа (SMA; английский: Senior High School или High School), является средним образованием в формальном образовании в Индонезии после окончания средней школы (или эквивалента). Старшая средняя школа занимает 3 года, начиная с 10 класса до 12 класса. Студенты могут выбрать желаемую школу и выбрать интересующую кафедру. Выпускники средней школы могут продолжить свое образование в колледже или прямо на работу. В основном старшеклассники в возрасте 16-18 лет. Средняя школа не входит в обязательную государственную программу,

8 Профрессионально-техническое высшее учебное заведение (Sekolah Menengah Kejuruan "SMK") является одной из форм единицы формального образования, которая организует профессиональное образование в системе среднего образования как продолжение ПМШ/МТС или других форм, эквивалентных или опережающих по результатам обучения признанные такими же/эквивалентными SMP/MTs. B SMK есть много программной экспертизы.

${ }^{9}$ Медресе Алия "Madrasah Aliyah" (сокращенно МА) является средним образованием в формальном образовании в Индонезии, эквивалентом средней школы, которая управляется министерством по делам религий. Образование медресе Алии достигалось в течение 3 лет, начиная с 10 класса до 12 класса. Выпускники медресе Алия могут продолжить свое образование в государственных университетах, исламских университетах или непосредственно на работу. МА как средняя школа, есть ma public часто называют MA и MA профессиональное образование. Учебная программа медресе Алия вместе с учебной программой средней школы, просто на ма есть часть больше об Исламском религиозном образовании. 
Нормативно-Политические Вопросы Обращение С Обеспечением Низкого Образования В Индонезии (Policy In Handling The Low Education Relevance In Indonesia)

\begin{tabular}{|c|c|c|c|c|c|c|c|c|c|}
\hline класс & возраст & $\begin{array}{c}\text { клас } \\
\text { с }\end{array}$ & $\begin{array}{c}\text { возрас } \\
\text { т }\end{array}$ & $\begin{array}{c}\text { клас } \\
\text { с }\end{array}$ & $\begin{array}{c}\text { возрас } \\
\text { т }\end{array}$ & $\begin{array}{c}\text { клас } \\
\text { с }\end{array}$ & $\begin{array}{c}\text { возрас } \\
\text { т }\end{array}$ & класс & возраст \\
\hline $\mathrm{KB}$ & 4 & $\begin{array}{c}1 \\
\text { класс }\end{array}$ & 7 & $\begin{array}{c}7 \\
\text { класс }\end{array}$ & 13 & $\begin{array}{c}10 \\
\text { класс }\end{array}$ & 16 & $\begin{array}{c}\text { Степень } \\
\text { бакалавра }\end{array}$ & $\begin{array}{l}\text { разный возраст } \\
\text { (примерно } 4 \text { года) }\end{array}$ \\
\hline $\begin{array}{c}\text { Группа } \\
\text { A }\end{array}$ & 5 & $\begin{array}{c}\text { Клас } \\
\text { с } 2\end{array}$ & 8 & $\begin{array}{c}\text { Клас } \\
\text { с } 8\end{array}$ & 14 & $\begin{array}{c}11 \\
\text { класс }\end{array}$ & 17 & Magister & $\begin{array}{lr}\text { разный } & \text { возраст } \\
\text { (примерно } 2 \text { года) }\end{array}$ \\
\hline \multirow[t]{4}{*}{$\begin{array}{c}\text { Группа } \\
\text { Б }\end{array}$} & 6 & $\begin{array}{c}3 \\
\text { класс }\end{array}$ & 9 & $\begin{array}{c}9 \\
\text { класс }\end{array}$ & 15 & $\begin{array}{c}12 \\
\text { класс }\end{array}$ & 18 & врач & $\begin{array}{l}\text { разный возраст } \\
\text { (примерно } 3 \text { года) }\end{array}$ \\
\hline & & $\begin{array}{c}4 \\
\text { класс }\end{array}$ & 10 & & & & & & \\
\hline & & $\begin{array}{c}5 \\
\text { класс }\end{array}$ & 11 & & & & & & \\
\hline & & $\begin{array}{c}6 \\
\text { класс }\end{array}$ & 12 & & & & & & \\
\hline
\end{tabular}

\section{Б. МЕТОДЫ}

Этот документ вкдючает в себя нормативные подходы к правовым исследованиям, то есть правовому анализу посредством изучения библиотечных документов или дополнительной информации, как основного вида деятельности. Обзор нормативного права - это научный эмпирический подход к поиску доказательной теории юридической науки с нормативной точки зрения (Soekanto, 2015: 13-14). В результате данное исследование варьируется с точки зрения положительных юридических требований к национальной системе регудирования (Marzuki, 2016: 59). Используемые инструменты - судебная система и индивидуальный подход. Вторичные доказательства широко используются в качестве основных юридических знаний в соответствии с законами и правилами о искоренении коррупции и решениями суда. Собранные данные подвергаются качественному анализу.

\section{С. РЕЗУ ЛЬТАТЫ И ОБСУЖДЕНИЕ}

\section{1. Почему актуальность образования в Индонезии невысока}

Образование, по сути, является попыткой сохранить культурные ценности в обществе. Человек как главный вклад в воспитание психодогически является существом, способным мыслить, вести себя и обладать потенциалом. Тогда после окончания как то, что должно быть достигнуто это человек с самостоятельностью вкдючает в себя способность понять себя, перенаправить себя и адаптироваться к окружающей среде, 
где бы он ни был. Школа как функциональное учреждение, на которое возложены функции по развитию потенциала дичности, достижению идеалов и сохранению ценностно-культурной ценности, получила огромный вклад со стороны общества.(Пидарта, 2013: 1).

В этом случае сообщество не только обеспечивает вклад учащихся, но и другие ресурсы, необходимые для выподнения обязанностей и ответственности школы. Аучше поставить морально в виде поддержки, принятия, участия и так далее. Или входной материал в виде помощи, финансирования, инфраструктуры и так далее. Цель образования, которым управляет школа, должна иметь отношение к жизни дюдей. Вопрос актуальности здесь заключается в том, что школа имеет цель, основанную на потребностях, и способна оптимально расширить возможности сообщества.

Соответствующее образование в идеале должно быть способно породить человека-масуса, который имеет конкуренцию, соответствующую в ответ на вызовы и потребности своей эпохи. Актуальность должна иметь вид на будущее. Например, в школах преподают язык на всех уровнях образования, потому что язык явдяется универсальным. Где бы мы ни находились, средства массовой информации, используемые для общения, - это язык. Хотя, возможно, используемый язык отличается в зависимости от места и потребностей. Или урок математики, который учит людей делать прогнозы на будущее. Затем на базовом уровне ребенка обучают основным понятиям арифметики, а затем развивают в соответствии с уровнем, уровнем, потребностями и возможностями.

По данным Центрального бюро статистики Индонезии 2019 года, уровень открытой безработицы (ТРК), Индонезия в феврале 2019 года на 5,01\%, упал на 0,12 процентных пункта по сравнению с февралем и на 0,33 процентных пункта по сравнению с августом 2018 года. Факторы высокой численности безработных выпускников профессионально-технического вуза (ПТУ), как сообщило Центральное бюро статистики (ЦБС) некоторое время назад, оказались обусловлены многими аспектами. Хорошие аспекты предложения (инвентаризация) и аспект спроса (спрос).

Что касается предложения, то генеральный директор Министерства образования и культуры Республики Индонезия Хамид Мухаммад показывает, что есть четыре вещи, которые влияют. 
Во-первых, был переизбыток, то есть выпускники профтехучидищ специализировались в определенном превышении количества, чем остальные. Второй фактор-несовместимость профотдела с конкретными отраслевыми потребностями региона. Тогда третий выпуск по качеству выпускников не соответствует отраслевым стандартам, а четвертый выпуск по возрасту выпускников в среднем составляет всего 17 лет, поэтому придется ждать еще 1 год, чтобы работать. (Газета Кompas.com Издание 11 Марта 2019 Года).

Использование высоких технологий может способствовать изменению состава работников в зависимости от видов должностей и квалификации. В развивающихся странах доля неквалифицированных рабочих, операторов и ремесленников по-прежнему выглядит доминирующей. Однако рост отрасли требует мастерства, мастерства, профессионализма, интеллектуальной и творческой мощи на высоком уровне. Пожертвования техников медленно заменяют неквалифицированных рабочих и неквалифицированных рабочих (неквалифицированных рабочих), которые продолжают уменьшаться. Обрабатывающая промышленность и высокотехнологичные отрасли промышленности, в Индонезии Также начали расти творческие отрасли как один из лучших вариантов для стимудирования национальной производительности. Креативные индустрии также могут расширить возможности трудоустройства выпускников образовательных учреждений растет с каждым годом. Актуальность образовательных программ необходимо повышать, направляя образовательную программу на развитие креативности, креативности и способности к непрерывному обучению как основы для развития творческих индустрий.

Актуальность образования заключается в соответствии между образованием и развитием в обществе. Например: учебные заведения не могут выпускать выпускников, готовых к использованию. отсутствие соответствия выпускного (выпускного) образования требованиям экономического развития. Проблема актуальности этого в принципе достаточно принципиальна. В современном состоянии этого столь необходимого образования выход в соответствии с требованиями сообщества особенно в сочетании с подготовкой работы.

Усилия по повышению актуальности в системе образования направлены на приведение результатов образования в соответствие с потребностями обучающихся, в том смысле, что образовательный процесс может вдиять на удовлетворение потребностей обучающихся, как 
нуждающихся в труде, жизни общества, так и продолжающих свое высшее образование (Кадыр, 2012: 155).

Актуальность с точки зрения соотношения выпускаемых выпускниками образовательных единиц к ожидаемым единицам образования в ИТ или учреждениях, нуждающихся в рабочей силе, как количественно, так и качественно. Вопрос актуадьности виден из числа выпускников образовательного учреждения, которые не готовы к познавательным способностям и техническим переходам в образовательное учреждение на нем. Вопрос актуадьности может быть также известен по количеству выпускников конкретного образовательного учреждения, т. е. профессионально-технических училищ и высших учебных заведений, которые еще не готовы или даже не готовы работать. Это проблема, связанная с актуальностью (пригодностью) владения знаниями, навыками и отношением выпускников школы к потребностям общества (трудовым потребностям). Пример: в случае с компаниями все равно придется тратить на обучение иди стажировку будущих сотрудников, потому что они считаются не имеющими навыков работать так, как ожидалось. Уместные середины уместные, крючки вязания крючком, и полезные сразу.

Перед образованием стоит задача подготовки людских ресурсов к развитию. Шаг развития всегда осуществдяется в соответствии с сегодняшними требованиями. Время всегда ставит новые задачи, которые так часто не предвидятся ранее.

Актуальность образования - это степень, в которой система образования может производить продукцию в соответствии с потребностями строительства, а именно с такими проблемами, которые описаны в формулировке национальных целей в области образования. Образование, как ожидается, заполнит все сектора развития такого разнообразного производственного сектора, тогда актуальность образования считается высокой. Актуальность образования можно увидеть в том, чтобы следовать принципу "затраты-процесс-выпуск".

\section{2. вопросы и проблемы актуадьность образования в Индонезии в настоящее время}

В соответствии с выводами, полученными из настоящего документа, выдвигаются некоторые выводы, касающиеся актуальности образования, основанные на типе, пути и уровне образования следующим образом. 


\section{Первый: базовое образование}

Правительство должно предоставлять базовые образовательные услуги высокого качества, равноправные и справедливые, соответствующие потребностям выпускников как граждан общества и государства. Базовое образование формирует характер, образование базовой грамотности и базовых навыков для всех граждан через качественные образовательные услуги и правосудие. Справедливые услуги не раздичают этническую принадлежность, класс, под и социально-экономическое положение учащихся.

Критерии успешности актуальность базового образования закдючается не в размере количества школьных зданий, учителей, обучающихся, а в большом количестве знаний, которые должны быть усвоены учащимися, но более важным является формирование характера и базовой способности обучающихся к выполнению своих прав и обязанностей как ответственных граждан.

Однако действительность на местах проявляла признаки беспокойства. Единицей базового образования стала машина, печатающая знания для учащихся. Базовое образование организатором понимается как "совокупность предметов" преподается учителями в начальных школах, средних школах, медресе начального уровня, медресе среднего уровня. Это понимание фактически сократило сущность базового образования, которое в сущности установидо характеры и основные способности к обучению, быть совокупностью теории учебного процесса и запоминания в классе дикукур через тест механического запоминания. Базовое образование никогда не будет актуальным и не послужит прочной основой как формирования характера, так и повышения качества образования на уровне-следующем уровне, если это государство останется.

Базовое образование-это формальная образовательная программа, начинающаяся для всех граждан государства с содержания образования, которое не организовано в виде набора предметов, но должно быть интегрировано в раздичные образовательные программы школьного уровня (school-base programs), а именно: (1) воспитание характера, (2) образование базовых навыков для обучения (basic literacy), (3) образование базовых знаний и (4) образование жизненных навыков как вариант. Базовое образование - это также образовательная программа, которая распространяется на все подразделения, тип и уровень образования, такие как образование по вопросам гражданства, религиозное образование, индонезийский язык и национальная история. 


\section{Второй: среднее образование}

Актуальность Высшей школы может быть проанализирована со стороны ее функции как образовательной единицы довузовской подготовки студентов к прододжению обучения в вузе или непрерывному образованию. Средняя школа как программа среднего образования, Средняя школа устанавливает и развивает всех потенциальных студентов, чтобы иметь прочную основу для научного мышления через процесс обучения, который является интенсивным и систематическим. Студентам не только дается много теории и знаний, которые запоминаются, а не количество теорий, которые были преподаны учителями (поглощение) в качестве меры успеха, но он имеет kecakapapan основу для поиска и исследования собственных полезных знаний через процесс обучения inquri и независимого. Базовые навыки должны быть выращены с помощью программ образования, учебных программ и обучения, а также подхода и процесса управления школой.

Образование в средней школе по-прежнему сталкивается с проблемами в отношении актуальности учебной программы, обучения и управления школой, что создает процесс обучения студентов, который имеет низкое качество (механическое обучение). В процессе обучения меньше растет потенциал и креативность студентов, но при этом преподносится теория и знания, которые запоминаются за счет заряда теоретического материала. Процесс обучения, как это уже стало “типичной " культурой обучения студентов в Индонезии, особенно в начальной и средней школе. Школа смогла создать процесс обучения удобным, интересным и увлекательным для студентов, чтобы учиться оптимально, так что низкие достижения студентов и впечатдяются все хуже в последнее время.

\section{3. Среднее профессионадьное образование (СМК)}

В образовательном процессе в системе среднего профессионального образования обозначены признаки, которые согласуются с тем, что программы в системе профессионального образования, изодированы от реальных потребностей бизнеса и промышленности. Образовательные программы "управляются предложением " из-за типа учебных программ, учебных материалов, способов преподавания, средств обучения, оценки и сертификации определяется поставщиком, а именно правительством. Программа профессионального образования в школе жесткая и не 
податливая к меняющимся потребностям полевой работы. Образовательные программы не были ориентированы на потребности изменения рынка труда, поэтому застряли в парадигме “стреляй в цель, которая движется" (нацелена на движущуюся цель). Количество сгустков и учебная программа "относительно фиксированная" не согласованы с потребностями изменения занятости-fox. Согласно статистике безработицы, профессионально-техническое училище является образовательным подразделением, которое породило самые высокие показатели безработицы (портал Министерства образования Республики Индонезия 2019).

Профессиональное образование через курсы или обучение жизненным навыкам (РКН) имеет отношение к потребностям полевой работы. Они более гибки и могут следовать изменяющимся потребностям полевых работ. Образовательные курсы в большей степени" ориентированы на спрос", поскольку тип образовательной программы меняется в связи с изменением потребностей получателей работы. Учебная программа курсовая работа и ССТ могут быть открыты и закрыты в соответствии с потребностями сообщества необходимо и сейчас.

Профессиональное образование в школах вызвало структурные проблемы, которые делают отсутствие актуальности с полевой работой. Развитие учебной программы происходит постоянно (постоянно), поскольку образование формируется юридически-формально, что может ограничить творческий потенциал руководителя программы и “избежать" изменений. Наоборот деловой мир постоянно меняется (переменный), даже новые технологии впервые вошии в мир бизнеса, потому что следуют требованиям рынка. С другой стороны, программы-курсы как провайдеры обучения имеют общую природу с миром бизнеса и промышленности, они “изменчивы” к требованиям меняющегося рынка. Поэтому интеграцию профессионального образования в профессиональнотехнические курсы необходимо рассматривать как политическую повестку дня развития профессионального образования в будущем.

4. высшее образование

Из высшего образования указаны симптомы, которые согласуются с тем, что, чем выше уровень образования рабочей силы, тем выше уровень безработицы. Это состояние является устойчивым в течение последних пяти лет, следствием возникновения симптомов дисбаланса между структурой предложения рабочей силы и структурой занятости по уровню образования. Хромой, потому что в то время, когда образование 
предлагает работникам выпускников высшего образования, занятость все еще существует, потому что оказывается, что больше нуждается в образованных рабочих низко даже не образованных вообще.

Согласно ISCO (International Classification of Occupation), есть признаки, которые являются последовательными; что национальное образование не развивает самостоятельность выпускников. Самостоятельность в попытках более точно сделать это у образованных невысока, хотя производительность труда невысока. Симптомы показали, что чем выше образование, тем ниже процент работников, которые пытаются самостоятельно. Этот симптом показывает, что инвестиции в образование оказывают негативное влияние на снижение независимости работников. Чтобы стимулировать выравнивание образования, то программы высшего образования должны быть в состоянии производить выпускников, которые являются независимыми и профессиональными. Дело совсем в обратном, самостоятельность рабочих-выпускников высших учебных заведений выросла не так, как ожидалось.

\section{D. ВЫВОДЫ}

Исследование актуальности послевузовского образования 2019 года, направлено на две составляющие образования в развитии качества человеческих ресурсов, а именно: (1) образование для подготовки инфраструктуры человеческих ресурсов как основы национальной системы образования; и (2) профессиональное образование как образовательный терминал, который включает в себя профессиональное, неформальное образование, профессиональное и высшее образование. Тем не менее, изучение актуальности высшего образования должно быть сделано специально с учетом сложности, которая не может быть решена с помощью этого исследования, потому что ресурсы очень ограничены.

\section{БИБЛИОГРАФИЯ}

https://id.wikipedia.org/wiki/Pendidikan_di_Indonesia

Anadra, Fellovy. 2011. Hubungan Antara Pendidikan dan Pertumbuhan Ekonomi.http://kantawbackup.blogspot.co.id/2011/07/hubungan-antarapendidikan-dan.html.diakses. diakses pada tanggal 18 Oktober 2016 pukul 06.37. 
Asra. 2014. Efisiensi Pendidikan. http://www.asraraspia.web.id/2014/01/efisiensipendidikan.html. diakses pada tanggal 13 September 2019 pukul 14.22.

Danim, Sudarwan. 2018. Ekonomi Sumber Daya Manusia. Bandung: Pustaka Setia.

Fattah, Nanang. 2009. Ekonomi dan Pembiayaan Pendidikan. Bandung: Remaja Rosdakarya.

Fazan.

2019. Hubungan

Kebudayaan

dengan

Pendidikan. http://fazan.web.id/hubungan-kebudayaan-denganpendidikan.html.

Hasbullah. 2016. Dasar-dasar Ilmu Pendidikan. Jakarta: Raja Grafindo

Kadir, Abdul. 2018. Dasar-dasar Pendidikan. Jakarta: Kencana Prenada Media Group.

Pidarta, Made. 2013. Landasan Kependidikan: Stimulus Ilmu Pendidikan Bercorak Indonesia. Jakarta: Rineka Cipta.

Suhartono, Suparlan. 2009. Filsafat Pendidikan. Yogyakarta: Ar-Ruzz Media.

Suryadi, Ace. 1999. Pendidikan Investasi SDM dan Pembangunan. Balai Pustaka: Jakarta. 
Indrayanto, Smyshlyaeva Larisa Germanovna

470 - JURNAL CITA HUKUM (Indonesian Law Journal). Vol. 8 Number 2 (2020). P-ISSN: 2356-1440.E-ISSN: 2502-230X 